\title{
International Journal of
}

\section{Computer Network and Information Security}

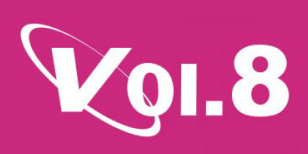

No. 3 Mar. 2016

\section{IJCNIS Vol.8}

Http:// www.mecs-press .org

Vol. 8 No.3 March 2016
Modern Education and Computer Science PRESS 
International Journal of Computer Network and Information Security (IJCNIS)

ISSN Print: 2074-9090, ISSN Online: 2074-9104

Volume 8, Number 3, March 2016

\section{Contents}

\section{REGULAR PAPERS}

Predict Link Failure in AODV Protocol to provide Quality of Service in MANET

Sedrati Maamar, Benyahia Abderezzak

Optimized Communication of Group Mobility in WPAN

Suman Lata, Naveen Goel

Buffering Strategies in Optical Packet Switching

Double Layer Image Security System using Encryption and Steganography

Samreen Sekhon Brar, Ajitpal Brar

Analysis of Cryptographic Protocols AKI, ARPKI and OPT using ProVerif and AVISPA

Amol H. Shinde, A. J. Umbarkar

A Stable Backbone-Based on Demand Multipath Routing Protocol for Wireless Mobile Ad Hoc Networks

Sujata V. Mallapur, Siddarama R. Patil, Jayashree V. Agarkhed

An Analysis of Link Disjoint and Node Disjoint Multipath Routing for Mobile Ad Hoc Network

Indrani Das, D.K. Lobiyal, C.P.Katti 